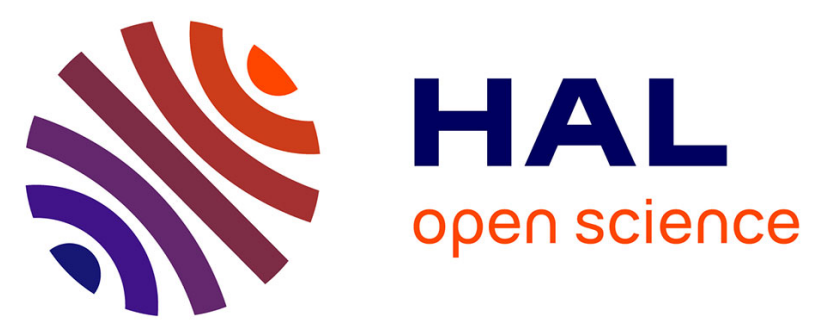

\title{
Predictive model for tensile strength of pharmaceutical tablets based on local hardness measurements
}

Audrey Juban, Cécile Nouguier-Lehon, Stéphanie Briancon, Thierry Hoc, François Puel

\section{- To cite this version:}

Audrey Juban, Cécile Nouguier-Lehon, Stéphanie Briancon, Thierry Hoc, François Puel. Predictive model for tensile strength of pharmaceutical tablets based on local hardness measurements. International Journal of Pharmaceutics, 2015, 490 (1-2), pp. 438-445. 10.1016/j.ijpharm.2015.05.078 . hal-01273157

\section{HAL Id: hal-01273157}

https://hal-centralesupelec.archives-ouvertes.fr/hal-01273157

Submitted on 13 Apr 2017

HAL is a multi-disciplinary open access archive for the deposit and dissemination of scientific research documents, whether they are published or not. The documents may come from teaching and research institutions in France or abroad, or from public or private research centers.
L'archive ouverte pluridisciplinaire HAL, est destinée au dépôt et à la diffusion de documents scientifiques de niveau recherche, publiés ou non, émanant des établissements d'enseignement et de recherche français ou étrangers, des laboratoires publics ou privés. 
To cite this article: A. JUBAN, C. NOUGUIER-LEHON, S. BRIANCON, T. HOC, F. PUEL, 2015 Predictive model for tensile strength of pharmaceutical tablets based on local hardness measurements International Journal of Pharmaceutics 490, 438-445

http://dx.doi.org/10.1016/j.ijpharm.2015.05.078

\title{
Predictive model for tensile strength of pharmaceutical tablets based on local hardness measurements
}

Audrey JUBAN ${ }^{a}$, Cécile NOUGUIER-LEHON ${ }^{b}$, Stéphanie BRIANCON ${ }^{a}$, Thierry HOC ${ }^{b}$, François PUEL ${ }^{a, c}$.

a Université de Lyon, F-69622 Lyon, France. Université Lyon 1, Villeurbanne, CNRS, UMR5007, Laboratoire d'Automatique et de Génie des Procédés (LAGEP), CPE-Lyon, 43 bd du 11 Novembre 1918, 69622 Villeurbanne Cedex, France

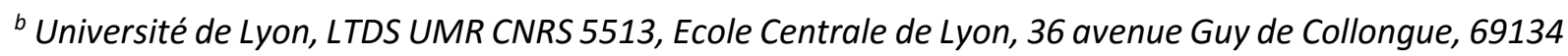
ECULLY cedex, France

c Université Paris Saclay, CentraleSupélec Paris, Laboratoire de Génie des Procédés et Matériaux (LGPM), EA 4038, Grande Voie des Vignes, 92290 Châtenay-Malabry, France

Corresponding author : Prof. F. Puel, +33 (0)1 411311 09, francois.puel@centralesupelec.fr

\begin{abstract}
In the pharmaceutical field, tablets are the most common dosage forms for oral administration. During the manufacture of tablets, measures are taken to assure that they possess a suitable mechanical strength to avoid crumbling or breaking when handling while ensuring disintegration after administration. Accordingly, the tensile strength is an essential parameter to consider. In the present study, microscopic hardness and macroscopic tensile strength of binary tablets made from microcrystalline cellulose and caffeine in various proportions were measured. A relationship between these two mechanical properties was found for binary mixture. The proposed model was based on two physical measurements easily reachable: hardness and tablet density. Constants were determined from the two extreme compositions of this given system. This model was validated with experimental results, and a comparison was made with the one developed by Wu et al. (2005). Both models are relevant for this studied system- Nonetheless, with this model, the tablet tensile strength can be connected with a tablet characteristic at microscopic scale in which porosity is not needed.
\end{abstract}




\section{Keywords}

Tablet tensile strength

Powder mixture

Predictive model

Direct compression

Nanoindentation

Diametral compression test

\section{Chemical compounds studied in this article}

Caffeine (PubChem CID: 2519); Microcrystalline cellulose (PubChem CID: 14055602) 


\section{Introduction}

In the pharmaceutical field, tablets are the most common dosage form for oral administration and these forms occupy two thirds of the global drug market (Wu and Seville, 2009). Tablets are composed of numerous particulate materials that are bound together under pressure in order to be delivered as a unit. The nature of these compounds (physical and chemical) as well as the processing conditions are crucial for the properties of the blend and, consequently, the tablet ones (Tejedor et al., 2015). For example, it is well known that the macroscopic dissolution of tablets depends on the physicochemical properties of the micrometric powders such as contact angle, surface area and particle size (Tran et al., 2015; Leonardi and Salomon, 2013). In the same way, recent studies have been conducted on mechanical properties (Tejedor et al., 2015; Al-khattawi et al., 2014; Sun, 2011; Narayan and Hancock, 2003). However, the relationship between mechanical properties at different scale is not yet fully understood. Concerning the processing conditions for the tablets manufacturing, the use of direct compression has rapidly increased in the past few years due to its economic interest and its process which avoids the steps of the wet granulation and drying processes.

During tablet manufacturing, measures are taken to ensure that tablets possess a suitable mechanical strength to avoid crumbling or breaking when handling. According to the European Pharmacopoeia (European Pharmacopeia, 2014) two mandatory tests are proposed to determine mechanical strength of tablets: friability of uncoated tablets and resistance to crushing of tablets based on diametral compression test (sections 2.9.7 and 2.9.8, respectively). The latter one, using a tablet tester, determines the force, usually expressed in Newton $(\mathrm{N})$, needed to disrupt tablets by crushing. The literature has suggested other tests for the practical determination of the mechanical strength of tablets like the three-point bending test, biaxial compression test, etc... (see Podczeck (2012) for a complete review). Nevertheless the diametral compression test is the easiest to implement.

A more thorough study of tablets requires the knowledge of other characteristics. Density; and porosity, were generally used to study the compression behaviour of the powder mixture corresponding to powder compactability and powder compressibility (ability to reduce their volume under pressure). In the literature, several studies dealt with the understanding of the compressibility according to the properties of the pure components. These studies were based on global models commonly used in the pharmaceutical field such as Heckel model (Heckel, 1961, llkka and Paronen, 1993, Van Veen et al., 2000) or Kawakita model (Kawakita and Lüdde, 1970, Frenning et al., 2009, Mazel et al., 2011, Busignies et al., 2012). However, Denny (2002) made a comparison between these two equations and finally concluded that Kawakita equation is a specific case of the modified Heckel equation. In addition, there is no proven relationship between the powder compressibility and the physical and mechanical properties of tablets. 
Many authors have been interested in the study of tablet tensile strength of binary mixtures, using the relative proportion of the two pure components (Chan et al., 1983; Kuentz and Leuenberger, 2000; Ramirez et al., 2004; Michrafy et al., 2007). In all these studies, several unknown parameters were needed. These parameters are not easily accessible such as characteristic parameters describing intrinsic interaction between particles (Chan et al., 1983) or critical relative density for models using percolation theory (Kuentz and Leuenberger, 2000; Ramirez et al., 2004; Michrafy et al., 2007).

In the same way, a simple model predicting the tensile strength of binary mixtures was developed by Wu et al. (2005). These authors have adapted the Ryshkewitch-Duckworth equation (Duckworth, 1953 ) in which tensile strength of tablets made from a single compound depended on their porosity, irrespective of the tablet dimensions. Using this approach two mixtures were studied: microcrystalline cellulose (MCC) / hydroxypropylmethyl cellulose (HPMC) and MCC / Starch, each for three compositions (90, 50 and $10 \mathrm{wt} \%$ of MCC and 80,50 and $20 \mathrm{wt} \%$ of MCC, respectively). Tablets were produced using an Instron universal testing machine and $800 \mathrm{mg}$ powder samples were compressed into a $13 \mathrm{~mm}$ die to a specified compression force ranging from $3 \mathrm{kN}$ to $18 \mathrm{kN}$ (corresponding to a compression load ranging from $22 \mathrm{MPa}$ to $135 \mathrm{MPa}$ ). A good estimation of the tablet tensile strength was obtained for the two studied systems with an overestimation of the tensile strength for high relative densities $(\geq 0.85)$.

The purpose of the present study was to develop a simplified model in order to predict the tensile strength of binary tablets from a local mechanical measurement performed at the surface of the tablet (i.e hardness) and the tablet density. The performance of the present model was compared to the one developed by $\mathrm{Wu}$ et al. (2005). The binary mixture contained anhydrous caffeine as the active pharmaceutical ingredient (API) and microcrystalline cellulose (Avicel ${ }^{\circledR} \mathrm{PH}-102, \mathrm{FMC}$ Biopolymer) as diluent. This model will be applied to predict the tablet tensile strength of a given system, for all compositions and within in a wide range of compression loads. 


\section{Materials and methods}

\subsection{Materials}

Two anhydrous caffeine crystalline forms exhibiting an enantiotropic relationship are known and called Form I, stable from about $145^{\circ} \mathrm{C}$ to its melting point $236^{\circ} \mathrm{C}$ (Pinto and Diogo, 2006) and Form II, stable from room temperature to $145^{\circ} \mathrm{C}$. The material used in this study was caffeine Form I (CFI). It was obtained using the same method than Hubert et al. (2013) (based on the one suggested by Derollez et al. (2005) and Griesser et al. (1999)) as follows. Commercial anhydrous caffeine Form II (purchased from Cooper) was heated to $170^{\circ} \mathrm{C}$ in an oven for 24 hours in order to anneal the Form II. Freshly Form I was quickly cooled in liquid nitrogen until room temperature. On each batch a Differential Scanning Calorimetry (DSC) analysis was performed at a heating rate of $10^{\circ} \mathrm{C} / \mathrm{min}$ from $20^{\circ} \mathrm{C}$ to $270^{\circ} \mathrm{C}$ and no trace of the transition $I I \rightarrow I$ was found. Microcrystalline cellulose (MCC), Avicel ${ }^{\circledR} \mathrm{PH}-102$, was obtained from FMC Biopolymer. For each pure component the true particle density $(\rho)$ was determined using a helium pycnometer (Hubert, 2012).

The particle size distribution for these two materials was measured with AeroS dry dispersion unit (Malvern Instruments, U.K.). Three measurements of the particle size distribution were performed on each powder. The resulting volume density distribution was averaged. Their minimum, mean and maximum diameters (respectively $d_{10}, d_{50}, d_{90}$ ) were calculated. Their values with their standard deviations are listed in Table 1.

\begin{tabular}{cccc}
\hline Powders & $\begin{array}{c}\mathbf{d}_{10}{ }^{a} \\
(\mu \mathrm{m})\end{array}$ & $\begin{array}{c}\mathbf{d}_{50}{ }^{a} \\
(\mu \mathrm{m})\end{array}$ & $\begin{array}{c}\mathbf{d}_{90}{ }^{a} \\
(\mu \mathrm{m})\end{array}$ \\
\hline CFI & $19.7 \pm 0.7$ & $67.8 \pm 2.1$ & $160.5 \pm 3.5$ \\
MCC & $28.3 \pm 0.1$ & $119.0 \pm 0.0$ & $268.7 \pm 1.2$ \\
\hline
\end{tabular}

${ }^{\mathrm{a}}$ Average calculated from 3 measurements

Table 1: Particle size distribution parameters of CFI and MCC ( $n=3)$ 


\subsection{Tablets preparation}

Cylindrical tablets were prepared with a binary mixture of anhydrous caffeine Form I (one day after its manufacture) and MCC as a diluent. These two materials were mixed in various proportions with caffeine content of $0,10,20,30,40,50,60,78,90$ and $100 \mathrm{wt} \%$. The blending was performed with a tridimensional mixer (Turbula ${ }^{\circledR} \mathrm{T} 2 \mathrm{~F}$ ) at a rotational rate of $49 \mathrm{rpm}$ for 10 minutes. The homogeneity of the blend was assessed by measuring the caffeine content after mixing by DSC. The measurements were realized in triplicate for each composition (three sampling performed in three positions in the mixing vial). The relative difference between the measure and the theoretical caffeine content was less than $5 \%$. All tablets were made at constant mass (about $300 \mathrm{mg}$ ) by using a compaction simulator Styl'One Classic (Medelpharm, Beynost, France) and its data acquisition software (Analis, 2.03 versions, Medelpharm). This tableting press was a single station press where compression was made by the lower punch. The compression forces were measured with an accuracy of $0.5 \%$ of full scale, and the displacements of the punches were monitored using Linear Variable Differential Transformers (LVDTs) with an accuracy of $50 \mu \mathrm{m}$ for the lower punch. Standard Euro $D$ tools with flat-faces and $11.28 \mathrm{~mm}$ of diameter were fitted on the simulator. The device deformation (including punch deformation) was taken into consideration and measured before each experiment to correct the values of the displacement. In the present study, tablets were produced with one main compression under three different compression forces $(5 \mathrm{kN}, 10 \mathrm{kN}, 20 \mathrm{kN})$ corresponding to a pressure of $50 \mathrm{MPa}, 100 \mathrm{MPa}$ and $200 \mathrm{MPa}$, respectively. In the following of this study, these three pressures will be called compression loads. 


\subsection{Tablet characterization}

Twenty tablets per composition at each compression load were made. The tablet weight, thickness and diameter were measured using respectively a scale (AX 105 DeltaRange ${ }^{\circledR} \pm 0.0001 \mathrm{~g}$, MettlerToledo, Greifensee, Switzerland) and a Mitutoyo micrometer (Absolute Digimatic ID-S Série 543-790B $\pm 0.003 \mathrm{~mm}$, Codima Roboflux, Décines, France) just after compression according to the European Pharmacopeia methods section 2.09.05 (European Pharmacopeia, 2014).

The tablet density $d$ was calculated using Eq. (1); where $w$ is the weight and $V$ the volume of tablet.

$$
d=\frac{w}{V}
$$

The tablet porosity was calculated as follows (Eq. (2)):

$$
\varepsilon=1-\left(\frac{d}{\rho_{\text {blend }}}\right)
$$

where $\rho_{\text {blend }}$ is the particle density of the blend (i.e. mixture with no porosity), calculated using Eq. (3):

$$
\frac{1}{\rho_{\text {blend }}}=\frac{X_{C F I}}{\rho_{C F I}}+\frac{1-X_{C F I}}{\rho_{M C C}}
$$

where $\rho_{\mathrm{CF}}$ and $\rho_{\mathrm{MCC}}$ are the particle density of anhydrous caffeine Form I and microcrystalline cellulose particles, respectively, and $X_{C F I}$ is the mass fraction of anhydrous caffeine Form I in the mixture.

Table 2 shows the tablet characteristics. 


\begin{tabular}{|c|c|c|c|c|c|c|}
\hline Composition & $\begin{array}{l}\text { Compression } \\
\text { load } \\
\text { (P) }\end{array}$ & $\begin{array}{c}\text { Tablet } \\
\text { weight }^{b} \\
\text { (w) }\end{array}$ & $\begin{array}{c}\text { Tablet } \\
\text { thickness }^{\mathrm{b}} \\
\text { (t) }\end{array}$ & $\begin{array}{c}\text { Particle } \\
\text { density } \\
\text { calculated } \\
\left(\rho_{\text {blend }}\right)\end{array}$ & $\begin{array}{l}\text { Tablet } \\
\text { density }^{\mathrm{b}} \\
\text { (d) }\end{array}$ & $\begin{array}{c}\text { Tablet } \\
\text { diameter }^{\mathrm{b}} \\
\text { (D) }\end{array}$ \\
\hline (wt\% CFI) & (MPa) & (mg) & $(\mathrm{mm})$ & $\left(\mathrm{g} . \mathrm{cm}^{-3}\right)$ & $\left(\mathrm{g} . \mathrm{cm}^{-3}\right)$ & $(\mathrm{mm})$ \\
\hline \multirow{3}{*}{100} & 200 & $301.8 \pm 1.7$ & $2.27 \pm 0.02$ & \multirow{3}{*}{$1.446^{\mathrm{a}}$} & $1.317 \pm 0.004$ & $11.35 \pm 0.00$ \\
\hline & 100 & $298.6 \pm 2.5$ & $2.38 \pm 0.02$ & & $1.240 \pm 0.003$ & $11.34 \pm 0.00$ \\
\hline & 50 & $303.0 \pm 2.3$ & $2.64 \pm 0.02$ & & $1.135 \pm 0.005$ & $11.34 \pm 0.00$ \\
\hline \multirow{4}{*}{90} & 200 & $301.3 \pm 4.4$ & $2.25 \pm 0.03$ & \multirow{4}{*}{1.457} & $1.325 \pm 0.005$ & $11.35 \pm 0.00$ \\
\hline & 150 & $300.4 \pm 1.6$ & $2.31 \pm 0.01$ & & $1.300 \pm 0.004$ & $11.34 \pm 0.00$ \\
\hline & 100 & $301.4 \pm 2.2$ & $2.41 \pm 0.02$ & & $1.237 \pm 0.004$ & $11.35 \pm 0.00$ \\
\hline & 50 & $302.3 \pm 2.6$ & $2.63 \pm 0.02$ & & $1.134 \pm 0.003$ & $11.35 \pm 0.00$ \\
\hline \multirow{3}{*}{78} & 200 & $293.2 \pm 4.5$ & $2.18 \pm 0.03$ & \multirow{3}{*}{1.470} & $1.328 \pm 0.003$ & $11.35 \pm 0.01$ \\
\hline & 100 & $294.0 \pm 4.5$ & $2.40 \pm 0.03$ & & $1.210 \pm 0.006$ & $11.36 \pm 0.01$ \\
\hline & 50 & $297.0 \pm 2.9$ & $2.68 \pm 0.02$ & & $1.090 \pm 0.002$ & $11.37 \pm 0.01$ \\
\hline \multirow{3}{*}{60} & 200 & $301.2 \pm 2.3$ & $2.22 \pm 0.02$ & \multirow{3}{*}{1.490} & $1.347 \pm 0.002$ & $11.34 \pm 0.00$ \\
\hline & 100 & $300.4 \pm 2.3$ & $2.42 \pm 0.02$ & & $1.225 \pm 0.004$ & $11.35 \pm 0.00$ \\
\hline & 50 & $302.4 \pm 1.8$ & $2.75 \pm 0.01$ & & $1.084 \pm 0.003$ & $11.36 \pm 0.01$ \\
\hline \multirow{3}{*}{50} & 200 & $304.5 \pm 1.4$ & $2.21 \pm 0.01$ & \multirow{3}{*}{1.501} & $1.365 \pm 0.003$ & $11.34 \pm 0.00$ \\
\hline & 100 & $305.2 \pm 1.8$ & $2.43 \pm 0.02$ & & $1.242 \pm 0.002$ & $11.35 \pm 0.00$ \\
\hline & 50 & $304.1 \pm 3.5$ & $2.76 \pm 0.04$ & & $1.087 \pm 0.004$ & $11.37 \pm 0.00$ \\
\hline \multirow{3}{*}{40} & 200 & $301.9 \pm 2.9$ & $2.19 \pm 0.02$ & \multirow{3}{*}{1.513} & $1.362 \pm 0.004$ & $11.35 \pm 0.00$ \\
\hline & 100 & $302.1 \pm 2.6$ & $2.42 \pm 0.02$ & & $1.231 \pm 0.003$ & $11.37 \pm 0.00$ \\
\hline & 50 & $300.4 \pm 2.8$ & $2.79 \pm 0.03$ & & $1.057 \pm 0.002$ & $11.38 \pm 0.00$ \\
\hline \multirow{3}{*}{30} & 200 & $301.0 \pm 2.7$ & $2.16 \pm 0.02$ & \multirow{3}{*}{1.525} & $1.385 \pm 0.004$ & $11.33 \pm 0.00$ \\
\hline & 100 & $300.2 \pm 2.3$ & $2.38 \pm 0.02$ & & $1.246 \pm 0.004$ & $11.35 \pm 0.00$ \\
\hline & 50 & $302.0 \pm 1.3$ & $2.78 \pm 0.01$ & & $1.069 \pm 0.003$ & $11.37 \pm 0.00$ \\
\hline \multirow{3}{*}{20} & 200 & $304.3 \pm 2.7$ & $2.20 \pm 0.02$ & \multirow{3}{*}{1.537} & $1.372 \pm 0.002$ & $11.33 \pm 0.01$ \\
\hline & 100 & $304.4 \pm 1.9$ & $2.45 \pm 0.01$ & & $1.230 \pm 0.002$ & $11.35 \pm 0.00$ \\
\hline & 50 & $302.9 \pm 2.1$ & $2.89 \pm 0.02$ & & $1.032 \pm 0.002$ & $11.38 \pm 0.00$ \\
\hline \multirow{4}{*}{10} & 200 & $301.0 \pm 1.5$ & $2.15 \pm 0.01$ & \multirow{4}{*}{1.549} & $1.390 \pm 0.003$ & $11.33 \pm 0.00$ \\
\hline & 150 & $303.9 \pm 2.0$ & $2.26 \pm 0.01$ & & $1.324 \pm 0.003$ & $11.32 \pm 0.00$ \\
\hline & 100 & $298.9 \pm 2.7$ & $2.39 \pm 0.02$ & & $1.238 \pm 0.002$ & $11.35 \pm 0.00$ \\
\hline & 50 & $300.4 \pm 2.5$ & $2.84 \pm 0.03$ & & $1.041 \pm 0.004$ & $11.37 \pm 0.01$ \\
\hline \multirow{3}{*}{0} & 200 & $300.6 \pm 1.4$ & $2.15 \pm 0.01$ & \multirow{3}{*}{$1.561^{\mathrm{a}}$} & $1.389 \pm 0.004$ & $11.33 \pm 0.01$ \\
\hline & 100 & $301.9 \pm 2.9$ & $2.43 \pm 0.02$ & & $1.230 \pm 0.004$ & $11.35 \pm 0.01$ \\
\hline & 50 & $301.8 \pm 2.5$ & $2.93 \pm 0.03$ & & $1.016 \pm 0.004$ & $11.37 \pm 0.00$ \\
\hline
\end{tabular}

\footnotetext{
${ }^{a}$ Measured by helium pycnometry Hubert (2012)

${ }^{b}$ Average calculated from 20 tablets
}

Table 2: Tablet characteristics 


\subsection{Nanoindentation}

Nanoindentation tests were performed on tablets two days after their fabrication at ambient temperature using a commercial nanoindenter (Agilent Nanoindenter G200, ScienTec, Les Ulis, France). The Berkovich diamond tip had a pyramidal shape. Fused silica was used for calibration of the contact surface area. Indentation tests were performed on the surface of the tablets. Ninety indents (divided in ten areas) have been performed on the diametral line of the tablets (Figure 1) with a minimum spacing of $400 \mu \mathrm{m}$ of the borders and a minimum spacing of $200 \mu \mathrm{m}$ between each indentation print.

A constant strain rate of $0.05 \mathrm{~s}^{-1}$ and a maximum depth of $1.1 \mu \mathrm{m}$ were imposed. The Continuous Stiffness Measurement (CSM) method allows a determination of the Young's modulus and the hardness as functions of the displacement into the surface. In the present study, Oliver and Pharr's method was used (Oliver and Pharr, 1992) with the assumptions that apply to linear elastic isotropic materials. The elastic properties of the diamond indenter were $v_{i}=0.07$ and $E_{i}=1131 \mathrm{GPa}$. The hardness for each point was measured on the plateau between 3 and $9 \mu \mathrm{m}$. One measurement corresponded to 240 seconds. Indentations resulting in poor curves were not included in the analysis.

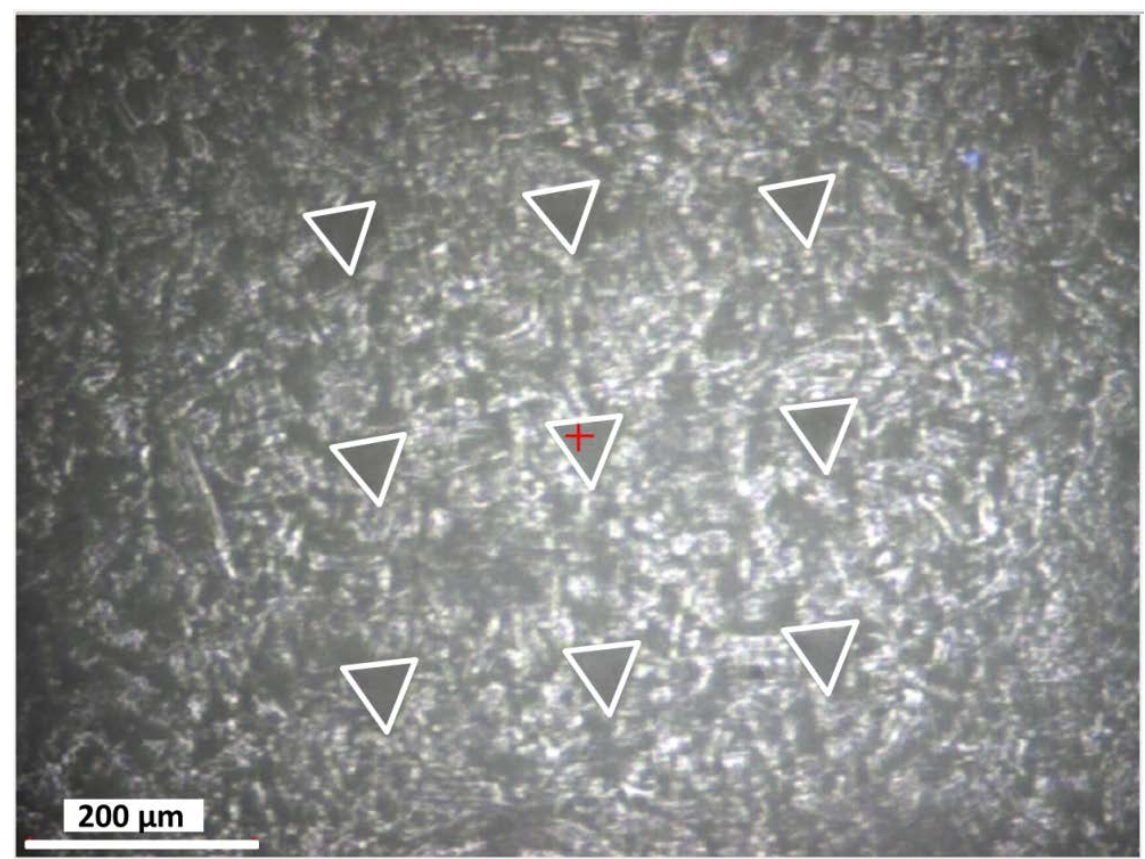

Fig.1: Microscopic observation showing the indent prints made by nanoindentation with a Berkovich tip (tablet 100wt\% excipient (MCC), compression load = $200 \mathrm{MPa}$ ) 


\subsection{Diametral compression test}

Diametral compression tests were performed on tablets one day after their fabrication at the ambient temperature using a tensile test device (ElectroPuls ${ }^{\mathrm{TM}} \mathrm{E} 10000$, Instron ${ }^{\circ}$, Élancourt, France) and its data acquisition software (WaveMatrix ${ }^{\mathrm{TM}}$, Instron ${ }^{\circ}$ ). A sensor of $1 \mathrm{kN}$ was used. Diametral compression tests were performed at a constant displacement rate of $0.01 \mathrm{~mm} \cdot \mathrm{min}^{-1}$ (to ensure a quasi-static test) with an acquisition rate of $10 \mathrm{~Hz}$. For each compression load (50 MPa, $100 \mathrm{MPa}$ and $200 \mathrm{MPa}$ ), a minimum of three tablets per composition were tested. The maximal diametral crushing force ( $F$ in Newtons) was measured for each tablet and the tensile strength ( $\sigma_{T}$ in $\mathrm{MPa}$ ) was calculated with Eq. (4)(Fell and Newton, 1970), where $D$ and $t$ were the diameter and the thickness of the tablet, respectively :

$$
\sigma_{T}=\frac{2 . F}{\pi \cdot D \cdot t}
$$

\subsection{Statistical analysis}

Statistical analyses were conducted using the $R$ (The $R$ foundation) with a threshold of $5 \%$ corresponding to the alpha risk. As all data were not normally distributed and variances were not equal, consequently, data could not be normalized, a non-parametric Kruskal-Wallis test was performed. In order to determine significant differences between mechanical properties of tablets and their compositions and compression pressures, a multiple comparison post hoc test (kruskalmc) was conducted. 


\section{Results}

\subsection{Tablet density}

Table 2 reports the tablet density for different caffeine contents at the three compression loads. A minimum of twenty tablets per composition, and per compression load were used to calculate the mean tablet density (using Eq. 1) and the standard deviations. As expected the tablet density increased with the compression load $\left(1.094 \pm 0.039 \mathrm{~g} . \mathrm{cm}^{-3}, 1.251 \pm 0.008 \mathrm{~g} . \mathrm{cm}^{-3}\right.$ and $1.375 \pm 0.027 \mathrm{~g} . \mathrm{cm}^{-3}$ for 50 MPa, $100 \mathrm{MPa}$ and $200 \mathrm{MPa}$ respectively). 


\subsection{Tablet hardness}

Hardness evolution with the caffeine content for each compression loads is given in Figure 2. The hardness increased with the compression load (mean values of $83 \pm 18 \mathrm{MPa}, 135 \pm 15 \mathrm{MPa}$ and $212 \pm$ $19 \mathrm{MPa}$ for $50 \mathrm{MPa}, 100 \mathrm{MPa}$ and $200 \mathrm{MPa}$, respectively) and also with the percentage of CFI. The effect of the compression load on the hardness was more important than the caffeine content.

For each pressure, statistical analyses of hardness in function of composition were performed and showed a significant difference between the two pure components; consequently, CFI was harder than MCC.

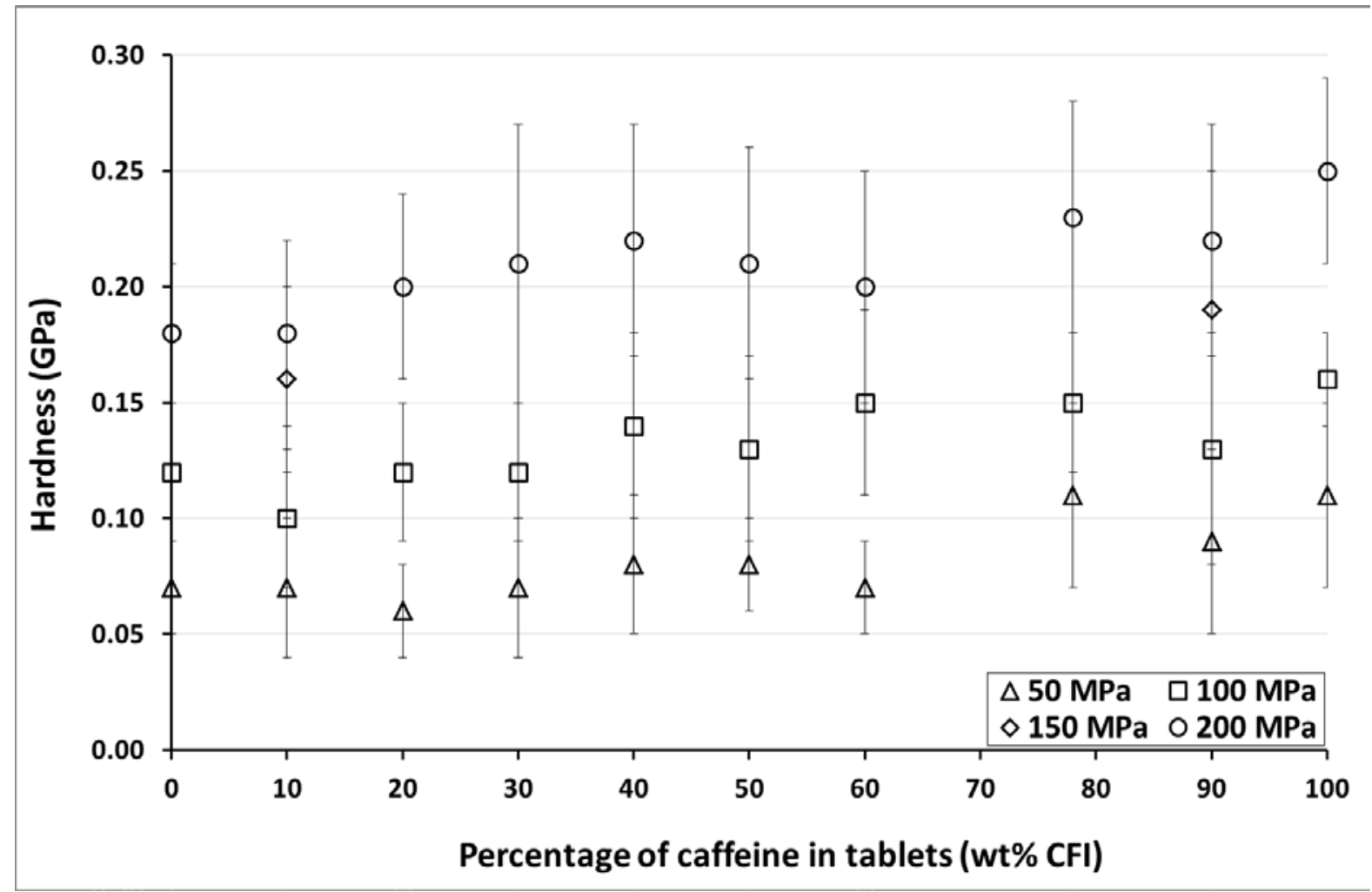

Fig.2: Evolution of surface hardness obtained by nanoindentation versus the percentage of CFI in tablets. 


\subsection{Tablet tensile strength}

The diametral compression test was performed to assess the influence of compression pressure and composition on the tablet resistance. All the tablets failed along a diametral line, parallel to the loading axis. The average tablet tensile strength obtained on a minimum of three tablets is given in Table 3 .

It can be observed in this table that the tensile strength increases with the increase in compaction pressure, whatever the composition. For example, the tensile strength measured for the two extremes compression pressure, increased of $55 \%$ and $79 \%$ for 100 wt $\%$ and 0 wt $\%$ of CFI, respectively. The relative variation in the tensile strength, between compression loads, was even more important for lower CFI percentages.

The values varied between 1.08 MPa to $2.02 \mathrm{MPa}, 1.85 \mathrm{MPa}$ to $5.06 \mathrm{MPa}$ and $2.40 \mathrm{MPa}$ to $9.76 \mathrm{MPa}$ for a compression load of $50 \mathrm{MPa}, 100 \mathrm{MPa}$ and $200 \mathrm{MPa}$, respectively. All results between $50 \mathrm{MPa}$ and $200 \mathrm{MPa}$ were significantly different. Whatever the compression pressure, tensile strengths for the two pure compositions were significantly different. A higher $\mathrm{CFI}$ amount in the powder mixture led to a lower tensile strength.

\begin{tabular}{ccccc}
\cline { 2 - 5 } & \multicolumn{5}{c}{ Compression load (MPa) } \\
\hline $\begin{array}{c}\text { Composition } \\
\text { (wt\% CFI) }\end{array}$ & $\mathbf{5 0}$ & $\mathbf{1 0 0}$ & $\mathbf{1 5 0}$ & $\mathbf{2 0 0}$ \\
\hline $\mathbf{0}$ & $\mathbf{2 . 0 0 \pm 0 . 0 7}$ & $5.04 \pm 0.11$ & - & $9.73 \pm 0.24$ \\
\hline $\mathbf{1 0}^{\mathbf{a}}$ & $1.69 \pm 0.06$ & $4.21 \pm 0.08$ & $6.34 \pm 0.11$ & $8.16 \pm 0.12$ \\
\hline $\mathbf{2 0}$ & $1.80 \pm 0.01$ & $4.27 \pm 0.06$ & - & $7.87 \pm 0.12$ \\
\hline $\mathbf{3 0}$ & $1.50 \pm 0.01$ & $3.60 \pm 0.06$ & - & $6.48 \pm 0.07$ \\
\hline $\mathbf{4 0}$ & $1.65 \pm 0.01$ & $3.79 \pm 0.04$ & - & $6.79 \pm 0.09$ \\
\hline $\mathbf{5 0}$ & $1.54 \pm 0.02$ & $3.34 \pm 0.06$ & - & $6.06 \pm 0.17$ \\
\hline $\mathbf{6 0}$ & $1.65 \pm 0.04$ & $3.34 \pm 0.12$ & - & $5.41 \pm 0.29$ \\
\hline $\mathbf{7 8}$ & $1.21 \pm 0.03$ & $2.56 \pm 0.02$ & - & $4.16 \pm 0.11$ \\
\hline $\mathbf{9 0}{ }^{\mathrm{a}}$ & $1.34 \pm 0.05$ & $2.36 \pm 0.09$ & $2.73 \pm 0.12$ & $3.20 \pm 0.10$ \\
\hline $\mathbf{1 0 0}$ & $1.08 \pm 0.11$ & $1.84 \pm 0.09$ & - & $2.39 \pm 0.29$ \\
\hline${ }^{a}$ Average calculated from 10 tablets & &
\end{tabular}

Table 3: Tablet tensile strength 


\subsection{Creation of a forecasting model of the tablet tensile strength}

The objective was to determine a link between the macroscopic tensile strength and the microscopic hardness in order to be able to predict a global characteristic of the tablets from the results obtained by a local measurement (nanoindentation test). The tablet density, which is an essential tablet characteristic, will be taken into account in the following of this study.

In the pharmaceutical field, the basis of direct compression is to add a key component (generally a diluent) in the formulation which has the necessary degree of fluidity and compressibility. Other ingredients could be included, such as lubricant, binder, glidant and/or disintegrating agent (Armstrong, 2002). Hence, at minimum two ingredients (API and diluent) are required in the formulation. To be consistent with the reality, binary mixtures (the two extreme compositions: 10 and $90 \mathrm{wt} \%$ of $\mathrm{CFI}$ ) were chosen in order to develop a simple model for predicting a mechanical property of tablets produced from powder mixtures. Figure 3 displays the tablet hardness multiplied by the density $(\mathrm{Hxd})$ according to the tensile strength of the tablets made at four compression loads. For each mixture, a linear regression through the origin was plotted (slopes of the equations and correlation coefficients are given in Table 4). The linear regression coefficient $\left(R^{2}\right)$ was always greater than 0.93 .

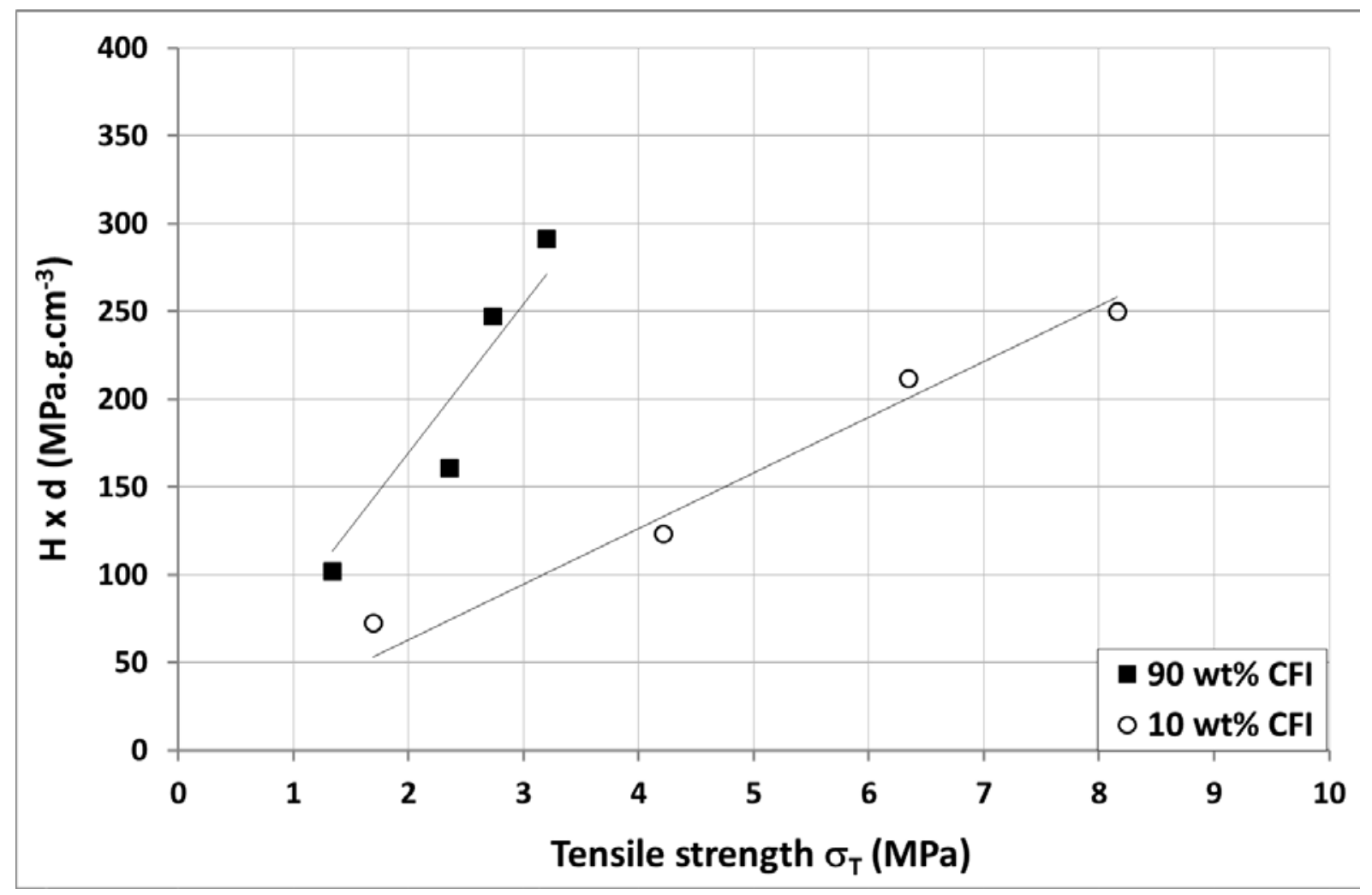

Fig.3: Evolution of tablet hardness multiplied by the tablet density $(H \times d)$ versus the tensile strength of the tablets. 


\begin{tabular}{cc}
\hline $\begin{array}{c}\text { Composition } \\
\text { (wt\% CFI) }\end{array}$ & $\begin{array}{c}\text { Slope } \\
\boldsymbol{\alpha}\end{array}$ \\
\hline 10 & 31.635 \\
90 & 84.738 \\
\hline
\end{tabular}

\section{Table 4: Linear regression parameters}

The equations obtained for these two linear regressions are of the type:

$H \times d=\alpha . \sigma_{T}$

where $\alpha$ is the slope of the linear regression. An increase of the slope $\alpha$ with the weight percentage of CFI ( wt\% CFI) was observed.

Then, assuming a linear relationship between these two quantities, the slope $\alpha$ can be expressed as:

$\alpha=a \cdot w t \% C F I+b$

with $a=0.6672$ and $b=24.693$.

By combining expressions (5) and (6), the tablet tensile strength was given by:

$\sigma_{T}=\frac{H \times d}{a . w t \% C F I+b}$

Equations 7 allowed to predict the value of a tablet tensile strength for a chosen system (binary mixture of $\mathrm{CFI}$ and $\mathrm{MCC}), \mathrm{H}$ and $\mathrm{d}$ being known. 


\section{4- Discussion}

The variation of the tensile strength according to the percentage of CFI was given in Figure 4. In this figure, experimental data were compared with the predicted ones calculated from Equation 7.

The two sets of data presented the same profile. Tablet tensile strength increased with the compression load and decreased when the CFI amount increased. These results were consistent with the ones shown by Sinka et al. (2009) where the aspirin tablet tensile strength increased with the compression pressure.

Predicted data were very close to the experimental ones especially for the two lower compression loads (50 MPa and $100 \mathrm{MPa}$ ). For the highest compression load the differences between experimental and predicted data was slightly higher for several compositions.

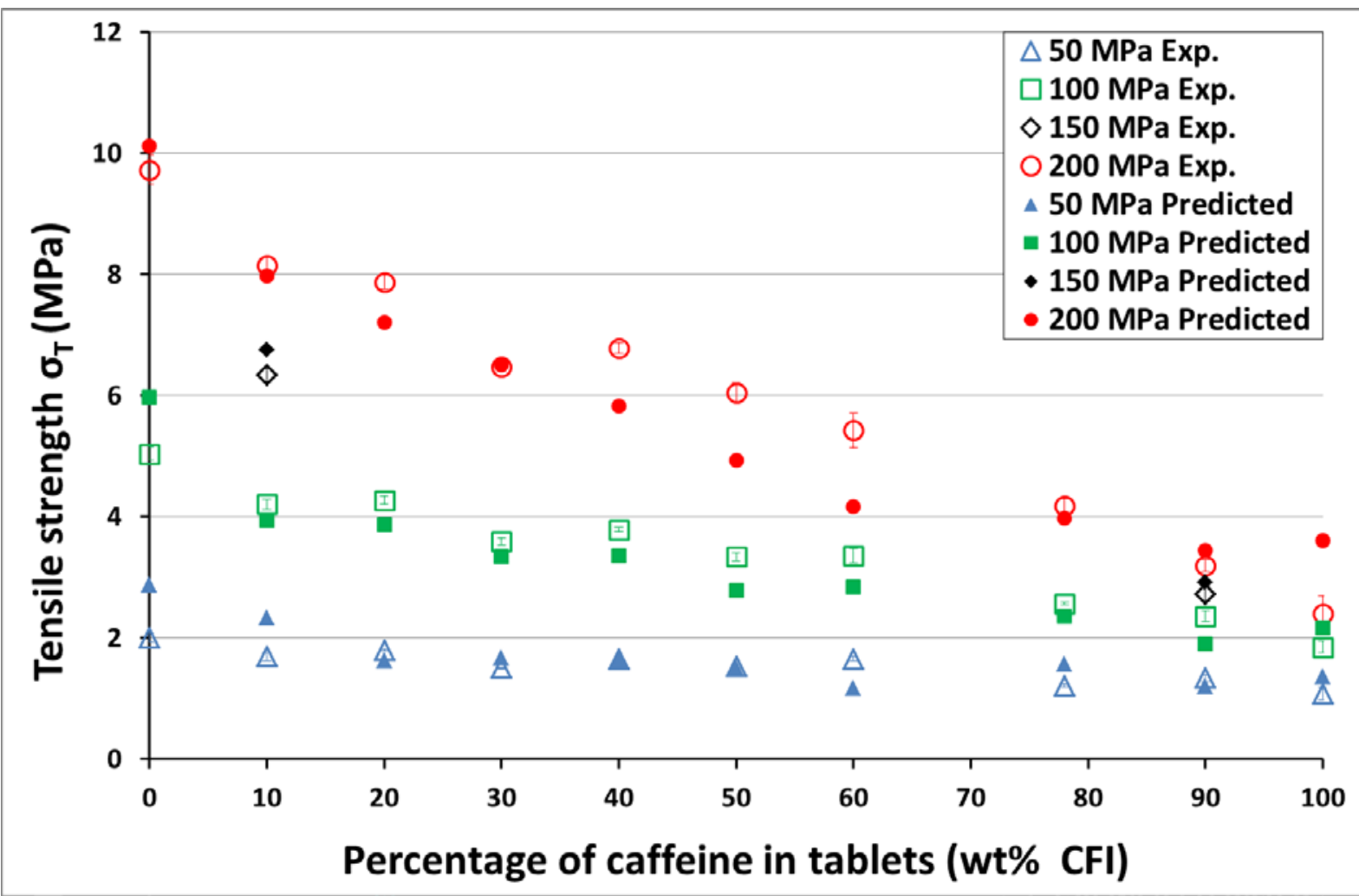

Fig.4: Evolution of predicted and experimental tensile strength obtained by diametral compression test (constant velocity of $0.1 \mathrm{~mm} \cdot \mathrm{min}^{-1}$ ) versus the percentage of CFI in tablets. 
In the literature, a simplified model predicting the tensile strength was developed by Wu et al. (2005). The authors adapted the Ryshkewitch-Duckworth equation for binary mixtures. Ryshkewitch (1953) found that the logarithm of the tensile strength of single compounds was inversely proportional to the porosity by plotting the tensile strength as a function of the porosity. In a discussion of Ryskewitch's results, Duckworth (1953) developed the following equation (Eq. 8) to correlate the tensile strength with the porosity for tablets made from a single component:

$\sigma_{t}=\sigma_{t 0} \cdot e^{-k \varepsilon}$

where $\varepsilon$ is the tablet porosity, $\sigma_{\mathrm{t} 0}$ is the tensile strength at zero porosity and $\mathrm{k}$ is a constant representing the bonding capacity. This latter parameter was fixed at 7 to reproduce all experimental data obtained by these authors on several materials. Wu et al. (2005) adapted this model for binary tablets and proposed the following equation (Eq.9):

$\sigma_{t m}=\sigma_{m 0} \cdot e^{-k_{m} \varepsilon}$

where $\sigma_{\mathrm{m} 0}$ and $\mathrm{k}_{\mathrm{m}}$ are the tensile strength at zero porosity and a constant representing the bonding capacity of the mixture, respectively. These two parameters were calculated by using the mixing rule and data obtained for pure components. In this model, a mixing rule was also used to calculate the true density of binary mixtures and therefore to calculate the tablet porosity $\varepsilon$.

Figure 5 compares our model with the one proposed by Wu et al. (2005) for the prediction of tablet tensile strength. Predicted data obtained with our model (based on Eq.7) and the ones calculated from $\mathrm{Wu}$ et al.'s model (2005) were plotted according to the experimental values of tensile strength measured in the present study. For both models, all points lie very close to the first bisector. The main difference between these models was observed for higher experimental values of tensile strength. Indeed, predicted values of tensile strength were underestimated with the newly developed model and overestimated with the one made by Wu et al.'s (2005). Thus, both models are relevant for the studied binary system (MCC/CFI). The mean relative deviation between predicted and experimental tensile strength is $12 \%$ for the developed model and $14.5 \%$ for the one proposed by Wu et al. (2005). In the present study, the proposed model has been derived from two physical measurements that are easily accessible (hardness and tablet density), while the Wu et al. model was mainly based on mixing rules for several parameters. It is worth to note that porosity (or tablet relative density) is not needed in our model. This parameter, measured on pure component powder, requires the use of a mixing rule to be approximated in the case of powder mixtures, and is often required in literature models. Moreover, the multiscale approach proposed in the present study showed that macroscopic tensile strength can be predicted using a local mechanical property (hardness obtained by nanoindentation technique) and tablet density. Most significantly, a good estimation of tensile strengths of binary 
tablets can be obtained from the proposed model, on a wide range of composition and compression loads (from $50 \mathrm{MPa}$ to $200 \mathrm{MPa}$ ) for the studied system. Furthermore, this model can also be extrapolated to estimate the tensile strengths for pure components.

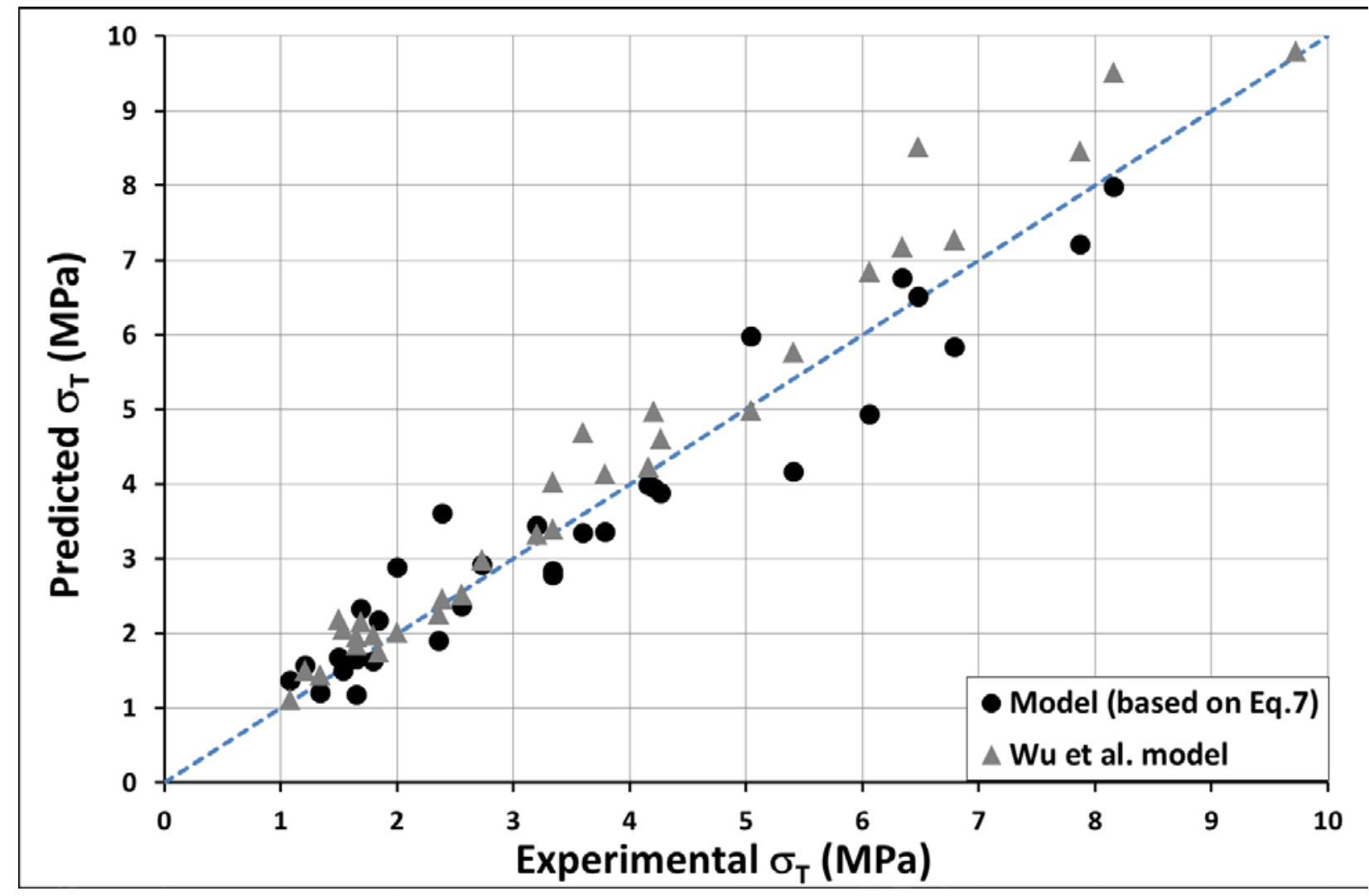

Fig.5: Evolution of predicted tablet tensile strength versus the experimental data for our model (based on equation 7) and the one made by Wu et al. (2005) 


\section{Conclusion}

In this work, hardness and tensile strength of binary tablets made from MCC and CFI in various proportions were measured. A relationship between these two mechanical properties has been established through an equation including tablet density and a simplified model was proposed.

The validity of this model was demonstrated with experimental data both for a wide range of compositions (from $10 \mathrm{wt} \%$ to $90 \mathrm{wt} \%$ of CFI) and a compression load from $50 \mathrm{MPa}$ to $200 \mathrm{MPa}$. Unlike existing models to predict tablet tensile strength (models based on Ryshkewitch-Duckworth equation or on the percolation theory), porosity is not needed. A comparison between our equation and the one reported by Wu et al. (2005) for the prediction of tablet tensile strength showed that both are applicable for the present studied system.

In this study, the tablet tensile strength can be connected with a tablet characteristic other than porosity. Indeed, tablet tensile strength (global characteristic) can be predicted from a local measurement on the tablets (tablet hardness).

\section{Acknowledgements}

The support of the Ministère de l'Enseignement Supérieur et de la Recherche is gratefully acknowledged. We would like to thank Medelpharm especially T. Ménard, G. Tardy and B. Villa as well as the engineers and technicians G. Conod-Nardi, B. Ponsard, O. Pollet and J.P. Valour for their technical support. We also wish to thank the IVTV platform (ANR-10-EQPX-06-01).

\section{References}

Al-Khattawi, A., Alyami, H., Townsend, B., Ma, X., Mohammed, A.R., 2014. Evidence-based nanoscopic and molecular framework for excipient functionality in compressed orally disintegrating tablets. PLoS One, vol.9, p. e101369

Armstrong, N.A., 2002. Tablet manufacture. In: Swarbrick J, ed. Encyclopedia of pharmaceutical technology, vol. 3. 3rd ed. New York: Informa Healthcare Inc., 2723.

Busignies, V., Mazel, V., Diarra, H., Tchoreloff, P., 2012. Prediction of the compressibility of complex mixtures of pharmaceutical powders. Int. J. Pharm., 436, 862-868.

Chan, S.Y., Pilpel, N., Cheng, D.C.-H., 1983. The tensile strengths of single powders and binary mixtures. Powder Technol. 34, 173-189. 
Denny, P.J., 2002. Compaction equations: A comparison of the Heckel and Kawakita equations. Powder Technol. 127, 162-172.

Derollez, P., Correia, N.T., Danede, F., Capet, F., Affouard, F., Lefebvre, J., Descamps, M., 2005. $A b$ initio structure determination of the high-temperature phase of anhydrous caffeine by $X-$ ray powder diffraction. Acta Crystallogr. B61, 329-334.

Duckworth, W., 1953. Discussion of Ryshkewitch paper. J. Am. Ceram. Soc. 36, 68.

European Pharmacopoeia, 2014. Eighth edn.

Fell, J.T., Newton, J.M., 1970. Determination of tablet strength by the diametrical compression test. J. Pharm. Sci. 59, 688-691.

Frenning, G., Nordstrom, J., Alderborn, G., 2009. Effective Kawakita parameters for binary mixtures. Powder Technol. 189, 270-275.

Griesser, U.J., Szelagiewicz, M., Hofmeir, U., Pitt, C., Cianferani, S., 1999. Vapor pressure and heat of sublimation of crystal polymorphs. J. Therm. Anal. Calorim. 57, 45-60.

Heckel, R.W., 1961. Density-pressure relationship in powder compaction. Trans. Metall. Soc. AIME 221, 671-675.

Hubert, S. Transitions de phases solides induites par un procédé de compression directe : application à la caféine et à la carbamazépine, PhD Thesis, University of Lyon 1, France, 2012.

Hubert, S., Briancon, S., Hédoux, A., Guinet, Y., Paccou, L., Fessi, H., Puel, F., 2011. Process induced transformations during tablet manufacturing: phase transition analysis of caffeine using DSC and low frequency micro-Raman spectroscopy. Int. J. Pharm., 420, 76-83.

Ilkka, J., Paronen, P., 1993. Prediction of the compression behaviour of powder mixtures by the Heckel equation. Int. J. Pharm. 94, 181-187.

Kawakita, K., Lüdde, K., 1970/71. Some considerations on powder compression equations. Powder Technol. 4, 61-68.

Kuentz, M., Leuenberger, H., 2000. A new theoretical approach to tablet strength of a binary mixture consisting of a well and a poorly compactable substance. Eur. J. Pharm. Biopharm. 49, 151-159.

Leonardi, D., Salomon, C.J., 2013. Comparison of different mathematical models for the tensile strength-relative density profiles of binary tablets. J. Pharm. Sci. 102, 1016-1023. 
Mazel, V., Busignies, V., Duca, S., Leclerc, B., Tchoreloff, P., 2011. Original predictive approach to the compressibility of pharmaceutical powder mixtures based on the Kawakita equation. Int. J. Pharm. 410, 92-98.

Michrafy, A., Michrafy, M., Kadiri, M.S., Dodds, J.A., 2007. Predictions of tensile strength of binary tablets using linear and power law mixing rules. Int. J. Pharm. 333, 118-126.

Narayan, P., Hancock, B.C., 2003. The relationship between the particle properties, mechanical behavior, and surface roughness of some pharmaceutical excipient compacts. Mater. Sci. Eng. A, 355, 24-36.

Oliver, W.C., Pharr, G.M. An improved technique for determining hardness and elastic modulus using load and displacement sensing indentation experiments. Journal of Materials Research Volume 7, Issue 06, 1992, pp 1564-1583

Pinto, S.S., Diogo, P., 2006. Thermochemical study of two anhydrous polymorphs of caffeine. J. Chem. Thermodyn. 38, 1515-1522.

Podczeck, F., 2012. Methods for the practical determination of the mechanical strength of tablets-from empiricism to science. Int. J. Pharm., 436, 214-232.

Ramirez, N., Melgoza, L.M., Kuentz, M., Sandoval, H., Caraballo, I., 2004. Comparison of different mathematical models for the tensile strength-relative density profiles of binary tablets. Eur. J. Pharm. Sci. 22, 19-23.

Ryshkewitch, E., 1953. Compression strength of porous sintered alumina and zirconia. J. Am. Ceram. Soc. 36, 65-68.

Sinka, I.C., Motazedian, F., Cocks, A.C.F., Pitt, K.G., 2009. The effect of processing parameters on pharmaceutical tablet properties. Powder Technol. 189, 276-284.

Sun, C.C., 2011. Decoding powder tabletability: roles of particle adhesion and plasticity. J. Adhes. Sci. Technol. 25, 483-499.

Tejedor, M.B., Nordgren, N., Schuleit, M., Rutland, M.W., 2015. Tablet mechanics depend on nano and micro scale adhesion, lubrication and structure. Int. J. Pharm., 486, 315-323.

Tran,T.H., Park, C., Kang, T., Park, Y.J., Oh, E., Lee, B.J., 2015. Micromeritic properties and instrumental analysis of physical mixtures and solid dispersions with adsorbent containing losartan: Comparison of dissolution-differentiating factors. Powder Technol. 272, 269-275.

Van Veen, B., Maarschalk, K.V.D.V, Bolhuis, G.K., Zuurman, K., Frijlink, H.W., 2000. Tensile strength of tablets containing two materials with a different compaction behavior. Int. J. Pharm., 203, 71-79. 
Wu, C.Y., Best, S.M., Bentham, A.C., Hancock, B.C., Bonfirld, W., 2005. A simple predictive model for the tensile strength of binary tablets. Eur. J. Pharm. Sci., 25, 331-336.

Wu, C.Y., Seville, J.P.K, 2009. A comparative study of compaction properties of binary and bilayer tablets. Powder Technol. 189, 285-294. 